\title{
DINÂMICA, QUALIDADE, PRODUÇÃo E CUSTO DE PRODUÇ̃̃o DE FORRAGEM DA MISTURA AVEIA PRETA E AZEVÉM ANUAL ADUBADA COM DIFERENTES FONTES DE NITROGÊNIO
}

\author{
DYNAMICS, QUALITY, PRODUCTION AND PRODUCTION COST OF OATS AND RYEGRASS \\ MIXTURE FERTILIZED WITH DIFFERENT SOURCES OF NITROGEN
}

\author{
André Brugnara Soares ${ }^{1}$ João Restle ${ }^{2}$ Cledson Roso $^{3}$ Gelci Carlos Lupatini ${ }^{4}$ \\ Dari Celestino Alves Filho ${ }^{5}$
}

RESUMO

\begin{abstract}
O experimento foi conduzido na Depressão Central do Rio Grande do Sul, de 21/04 a 02/06/94 (estabelecimento da pastagem) até 11/06/94 (período de utilização), com o objetivo de avaliar a dinâmica, a produção, a qualidade de forragem e o custo de produção da pastagem de aveia preta mais azevém, em pastejo contínuo, fertilizada com diferentes fontes de nitrogênio (uréia e sulfato de amônio) em cobertura. A mistura foi semeada de forma direta e adubada com $200 \mathrm{~kg} / \mathrm{ha}$ da fórmula 05-30-15. O nivel de nitrogênio em cobertura foi de $200 \mathrm{~kg} / \mathrm{ha}$ para ambas as fontes, sendo parceladas em três aplicações. A fonte de nitrogếnio não afetou, significativamente, a taxa de acumulação diária de matéria seca (MS) $(38,7$ e 36,1kg/ha de MS/dia), a produção total de forragem (7.410 e 6.618kg/ha de MS) e a qualidade da forragem. A porcentagem de MS foi de 18,26 e 18,47\%, o teor de proteína bruta, de 22,14 e 22,69\% e a digestibilidade in vitro da matéria orgânica, de 57,85 e 57,04\% para uréia $(U)$ e sulfato de amônio (SA), respectivamente. O custo total/ha da pastagem foi de $R \$ 295,70$ e $R \$ 379,40 ;$ o $N$ representando 36,08 e 50,20\%, para uréia e sulfato de amônio, respectivamente. $O$ custo/quilograma de MS produzida foi de $R \$ 0,039$ e $R \$ 0,057$ para pastagem em que foi utilizado a uréia e o sulfato de amônio, respectivamente. Conclui-se que, em pastagem de gramíneas anuais de inverno, a escolha da fonte de $N$ deve ser baseada no custo/kg de $N$.
\end{abstract}

Palavras-chave: custo, economia, pastagem cultivada, pastejo, sulfato de amônio, uréia.

\section{SUMMARY}

The experiment was conducted at the "Depressão Central do Rio Grande do Sul", from 04/21 to 06/02/94 (establishment of the pasture) until 11/06/94 (grazing period), with the objective to evaluate the dynamics, production, quality and the production cost of forage of the pasture of oat and ryegrass mixture, in continuous grazing, fertilized with different sources of nitrogen (urea or ammonium sulphate) applied as top dressing. The mixture was row-seeded (no-tilled) and fertilized with 200kg (05-30-15). Each source of nitrogen provided 200 $\mathrm{kg} / \mathrm{ha}$, divided in three applications. The source of nitrogen did not affect the daily dry matter (DM) accumulation rate (38.7 vs $36.1 \mathrm{~kg} / \mathrm{ha} / \mathrm{day}$ of $\mathrm{DM})$, the total forage production $(7.410 \mathrm{vs}$ $6.618 \mathrm{~kg}$ of DM/ha) and forage quality. The percentage of $D M$ was 18.26 vs $18.47 \%$, crude protein content was 22.14 vs $22.69 \%$ and the in vitro organic matter digestibility was 57.85 vs $57.04 \%$ for urea and ammonium sulphate, respectively. The total cost of the pasture was of $R \$ 295.70$ and $R \$ 379.40$, of which nitrogen fertilizer represented 36.08 and $50.20 \%$, for urea and ammonium sulfate, respectively. It can be concluded that for winter grass pastures, the choice of the source of nitrogen should be based on the cost $/ \mathrm{kg}$ of $N$.

Key words: ammonium sulfate, cost, winter pasture, economics, grazing, urea

\section{INTRODUÇÃO}

A exploração da pecuária de corte no Sul do Brasil fundamenta-se em pastagens naturais como a principal fonte de volumoso para os animais. No entanto, durante o período de inverno, as pastagens naturais ficam seriamente comprometidas,

\footnotetext{
${ }^{1}$ Engenheiro Agrônomo, Mestrando em Zootecnia, Universidade Federal Santa Maria (UFSM).

${ }^{2}$ Engenheiro Agrônomo, Ph.D., Professor Titular, Pesquisador do CNPq. Departamento de Zootecnia da UFSM, 97105-900, Santa Maria, RS. E-mail: restle@uol.com.br. Autor para correspondência.

${ }^{3}$ Engenheiro Agrônomo, Mestre em Zootecnia, PROGEPEC Consultores Associados Ltda.

${ }^{4}$ Engenheiro Agrônomo, Mestre em Zootecnia, UFSM, Professor do CEFET, Paraná.

${ }^{5}$ Engenheiro Agrônomo, Mestre em Zootecnia, UFSM, Professor do Departamento de Zootecnia da UFSM.
} 
tanto em termos quantitativos quanto qualitativos, devido à ocorrência de baixas temperaturas e geadas. Dessa forma, o uso de pastagens cultivadas de inverno pode ser uma ótima opção para proporcionar alimentação de qualidade no período em que os rebanhos estão sofrendo grande déficit alimentar. Em sistemas mais intensivos de produção, as pastagens cultivadas de inverno são usadas para redução da idade de abate ou de acasalamento e, quando manejadas de forma satisfatória, podem ser rentáveis economicamente, como demonstram RESTLE $\boldsymbol{e t}$ al. (1998), que obtiveram receitas líquidas/ha de $\mathrm{R} \$ 64,00$ e 117,00, durante o inverno, para terneiros e novilhos, respectivamente.

Devido ao mercado comum do Conesul, a competitividade na produção primária, mais especificamente na pecuária de corte, exige maior eficiência dos recursos forrageiros e financeiros, com redução da idade de acasalamento e de abate; caso contrário o produtor pode se descapitalizar ou mesmo abandonar a atividade. Baseando-se na necessidade do aumento da produtividade, o uso de pastagens cultivadas de inverno pode proporcionar ao produtor a venda de animais no período de entressafra.

A produtividade de uma pastagem é função de vários fatores, entre eles as condições climáticas, edáficas e de manejo. De uma forma geral, o fator que mais influencia na produtividade das pastagens é o conteúdo de nitrogênio $(\mathrm{N})$, por ser o nutriente mais limitante ao crescimento das plantas (MALAVOLTA, 1980).

A produtividade de espécies hibernais como a aveia preta (Avena strigosa) e o azevém anual (Lolium multiflorum), submetidas a doses de $\mathrm{N}$, sob pastejo, foram avaliadas por LUPATINI $\boldsymbol{e t}$ al. (1998), com respostas crescentes, em termos de produção de matéria seca $(4.893,9.327$ e $10.905 \mathrm{~kg} / \mathrm{ha}$ de $\mathrm{MS})$, para os níveis de $0,150 \mathrm{e}$ $300 \mathrm{~kg} / \mathrm{ha}$ de N. Os dados obtidos por RESTLE $\boldsymbol{e t}$ al. (1993) demonstram um bom retorno econômico da adubação nitrogenada nessas espécies.

A principal fonte de $\mathrm{N}$ utilizada na região sul do Brasil é a uréia. No entanto, em condições tropicais, quando usada em níveis elevados e com condições climáticas desfavoráveis, perdas de $\mathrm{N}$ por meio da volatilização, podem ser maiores em uréia quando comparada a outras fontes de $\mathrm{N}$ como o sulfato de amônio (ANJOS e TEDESCO, 1976). Os mesmos autores reportam perdas por volatilização de $\mathrm{N}$ de $30,3 \%$ contra menos de $1 \%$ quando foram usados a uréia e o sulfato de amônio, respectivamente. Essas perdas, após a fertilização, afetam o crescimento da pastagem e, conseqüentemente, o ganho de peso dos animais pode ser afetado.
Na implantação de pastagens de inverno, os custos são altos, principalmente quando são usados elevados níveis de nitrogênio. Dessa maneira, é necessário que esses recursos sejam utilizados de modo mais eficiente e racional. Como não existem, em nosso meio, informações a respeito do uso de fontes de $\mathrm{N}$ em pastagens cultivadas de inverno sob pastejo, o presente experimento teve como objetivo comparar a uréia e o sulfato de amônio como fontes de $\mathrm{N}$, e seus efeitos sobre a dinâmica, qualidade $\mathrm{e}$ produção da pastagem, bem como avaliar o custo de produção de forragem da pastagem da mistura aveia preta e azevém anual, sob pastejo.

\section{MATERIAL E MÉTODOS}

O experimento foi conduzido no Departamento de Zootecnia da Universidade Federal de Santa Maria, situada na Depressão Central do Rio Grande do Sul, (altitude de 95m, latitude 29 $43^{\circ}$ Sul e longitude $53^{\circ} 42^{\prime}$ Oeste) sobre solo podzólico vermelho-amarelo e clima Cfa (Subtropical úmido), conforme a classificação de Köppen (MORENO, 1961).

A instalação da pastagem foi por semeadura direta realizada no dia 21 de abril de 1994 sobre a resteva de pastagem de milheto (Pennisetum americanum), utilizando-se uma densidade de $60 \mathrm{~kg} / \mathrm{ha}$ de aveia preta (Avena strigosa) acrescida de $15 \mathrm{~kg} / \mathrm{ha}$ de azevém anual (Lolium multiflorum) em linhas espaçadas de $15 \mathrm{~cm}$, além de $15 \mathrm{~kg} / \mathrm{ha}$ de azevém semeado a lanço. A adubação de plantio constituiu-se da aplicação de $200 \mathrm{~kg} / \mathrm{ha}$ da fórmula 05-3015, na linha de semeadura, conforme as RECOMENDAÇÕES... (1989).

Foram comparados os tratamentos de adubação nitrogenada, usando-se uréia ou sulfato de amônio, na quantidade de $200 \mathrm{~kg}$ de nitrogênio/ha, parcelada em 3 aplicações; a primeira aplicação foi realizada no dia 20/05, durante o afilhamento da pastagem, quando foram aplicados $50 \mathrm{~kg} / \mathrm{ha}$ de $\mathrm{N}$, e as demais durante a utilização da pastagem (13/07 e $10 / 09$ ) com aplicações iguais de $75 \mathrm{~kg} / \mathrm{ha}$ de N. A dose total de $\mathrm{N}$ foi distribuída durante o período de crescimento da pastagem (maio a setembro), na primeira aplicação foi usada maior quantidade em relação às demais, devido ao fato de ocorrências de boas temperaturas no outono, que poderia ocasionar melhor resposta ao N. Cada tratamento ocupou uma área de cinco hectares, com cinco repetições de um hectare por tratamento, usando-se o delineamento inteiramente casualizado. A entrada dos animais ocorreu no dia 02/06, ou seja, 42 dias após a semeadura, usando-se terneiras das raças Charolês, Nelore e seus cruzamentos, com idade inicial de oito meses. 
O sistema de pastejo usado foi o contínuo com lotação variável, e uma oferta de forragem de aproximadamente 10\% (10kg de MS para cada $100 \mathrm{~kg}$ de peso vivo).

Os resíduos da pastagem foram avaliados a cada 28 dias aproximadamente (02/06, 02/07, 05/08, 25/08, 24/09, 21/09 e $06 / 11 / 94)$ por meio de cortes rente ao solo de dez amostras $\left(0,25 \mathrm{~m}^{2}\right)$ em cada piquete. Dessas amostras, foi retirada uma amostra composta para determinação do teor de matéria seca (MS) em estufa de ar forçado a $65^{\circ} \mathrm{C}$, teor de proteína bruta $(\mathrm{PB})$ pelo método micro Kjeldahl (AOAC, 1984) e digestibilidade "in vitro" da matéria orgânica (DIVMO), usando-se a técnica de TILLEY e TERRY (1963). Uma segunda amostra composta foi utilizada para a avaliação da composição botânica da pastagem, sendo as espécies separadas manualmente. Após a separação botânica, os componentes foram secos em estufa e pesados para determinação da composição botânica na base na matéria parcialmente seca.

A taxa de acumulação foi avaliada em período de aproximadamente 30 dias, utilizando três gaiolas de exclusão ao pastejo por piquete, adotando-se o método do triplo emparelhamento. A produção total de MS foi obtida pelo somatório das produções dos períodos (taxa de acumulação $\mathrm{x} \mathrm{n}^{\circ}$ de dias), mais o resíduo inicial, no momento da entrada dos animais na pastagem. $\mathrm{Na}$ análise econômica, foram utilizados os preços de mercado da época da realização do trabalho.

Os dados foram submetidos à analise de variância, sendo usado o seguinte modelo matemático: $Y_{i k j}=M+T_{i}+P_{k}+T_{i} P_{k}+E_{i k j}$, sendo que cada variável dependente $\left(\mathrm{Y}_{\mathrm{ikj}}\right)$ é igual a média de todas as observações (M), efeito dos tratamentos de índice ${ }_{\mathrm{i}}\left(\mathrm{T}_{\mathrm{i}}\right)$, efeito do período de índice ${ }_{\mathrm{k}}\left(\mathrm{P}_{\mathrm{k}}\right)$, efeito da interação entre tratamento de índice ${ }_{\mathrm{i}}$ e período de índice $_{\mathrm{k}}\left(\mathrm{T}_{\mathrm{i}} \mathrm{P}_{\mathrm{k}}\right)$ e efeito do erro aleatório associado a cada observação $\left(\mathrm{E}_{\mathrm{ikj}}\right)$.

Os dados foram analisados pelo método dos quadrados mínimos (SAS, 1990). Foi utilizado o teste de comparações de médias baseado no método dos quadrados mínimos em nível de 5\% de significância.

\section{RESULTADOS E DISCUSSÃO}

Os dados meteorológicos normais e os ocorridos no período experimental são apresentados na tabela 1 . Observa-se que a média de precipitação mensal ocorrida foi superior à normal em $46 \mathrm{~mm}$ durante esse período; apenas no mês de setembro ocorreu menor precipitação. Já a insolação ocorrida apresentou uma inferioridade de quatro horas de sol/mês, em relação à normal. As temperaturas máximas apresentaram comportamento normal durante os meses de estabelecimento e utilização da pastagem.

Não houve interação significativa entre tratamento e período para taxa de acumulação, produção de forragem, teor de PB e DIVMO. A taxa de acumulação média diária de matéria seca não foi afetada $(\mathrm{P}>0,05)$ pela fonte de nitrogênio usada, sendo que o crescimento da pastagem foi de 38,7 e $36,1 \mathrm{~kg} / \mathrm{ha}$ de MS/dia para uréia e sulfato de amônio, respectivamente (Tabela 2). Esses valores são inferiores aos encontrados por LESAMA (1997) na mistura de aveia preta mais azevém com $300 \mathrm{~kg} / \mathrm{ha}$ de $\mathrm{N}$, por ROSO (1998) que avaliou diferentes misturas forrageiras de gramíneas hibernais, usando $220 \mathrm{~kg} / \mathrm{ha}$ de $\mathrm{N}$ e por RESTLE $\boldsymbol{e t}$ al. (1998) que avaliaram diferentes categorias de bovinos de corte sob pastejo em aveia preta mais azevém. Os baixos valores obtidos neste trabalho, quando comparados aos trabalhos de ROSO (1998) e RESTLE et al.(1998), ocorreram basicamente por ser o primeiro ano de plantio direto nesta área, onde o solo não possuía a estrutura necessária para um bom desenvolvimento das plantas e pela competição com outras gramíneas presentes na área conforme mostra a tabela 3.

Como o sulfato de amônio é um fertilizante nitrogenado que contém $24 \%$ de enxofre (S), isso poderia se constituir em vantagem no uso desse fertilizante em relação à uréia. No entanto, não foi observado nenhum sintoma de deficiência de enxofre nas plantas de aveia preta e azevém, talvez pelo fato de que a maior parte dos solos do Rio Grande do Sul e de Santa Catarina sejam bem providos des- 
Tabela 2 - Resíduo inicial, taxa de acumulação e produção de forragem de uma pastagem de aveia preta + azevém submetida a duas fontes de adubação nitrogenada.

\begin{tabular}{|c|c|c|c|c|c|c|c|}
\hline \multirow[b]{2}{*}{ Tratamento } & \multirow[b]{2}{*}{$\begin{array}{c}\text { Resíduo } \\
\text { inicial } \\
\mathrm{kg} / \mathrm{ha} \text { de MS }\end{array}$} & \multicolumn{5}{|c|}{ Períodos } & \multirow[b]{2}{*}{ Média } \\
\hline & & $\begin{array}{l}02 / 06 \\
a \\
02 / 07\end{array}$ & $\begin{array}{c}02 / 07 \\
\text { a } \\
08 / 08\end{array}$ & $\begin{array}{c}08 / 08 \\
a \\
06 / 09\end{array}$ & $\begin{array}{c}06 / 09 \\
a \\
06 / 10\end{array}$ & $\begin{array}{l}06 / 10 \\
a \\
08 / 11\end{array}$ & \\
\hline \multirow{3}{*}{$\begin{array}{l}\text { Uréia } \\
\text { Sulfato de amônio } \\
\text { Média }\end{array}$} & \multicolumn{7}{|c|}{ Taxa de acumulação diária de MS (kg/ha/dia) } \\
\hline & & $\begin{array}{c}36,9 \\
36,9 \\
36,9 a^{*}\end{array}$ & $\begin{array}{c}27,5 \\
25,2 \\
26,4 \mathrm{~b}\end{array}$ & $\begin{array}{c}39,9 \\
40,6 \\
40,2 \mathrm{a}\end{array}$ & $\begin{array}{c}53,9 \\
35,0 \\
44,5 \mathrm{a}\end{array}$ & $\begin{array}{c}42,8 \\
39,7 \\
41,3 \mathrm{a}\end{array}$ & $\begin{array}{l}38,7 \\
36,1\end{array}$ \\
\hline & & \multicolumn{5}{|c|}{ Produção de MS (kg/ha) } & Total \\
\hline Uréia & 1098 & 1107 & 1018 & 1157 & 1618 & 1412 & 7410 \\
\hline Sulfato de amônio & 1042 & 1107 & 932 & 1177 & 1050 & 1310 & 6618 \\
\hline Média & 1070 & 1107 & 975 & 1167 & 1334 & 1361 & \\
\hline
\end{tabular}

*Médias na linha com letras diferentes diferem $(\mathrm{P}<0,05)$ pelo teste $\mathrm{t}$.

se elemento (RECOMENDAÇÕES..., 1989). Também deve ser considerado que o solo da área do experimento apresentou cerca de 3\% de matéria orgânica, que é uma fonte indireta de enxofre para as plantas.

Observa-se um decréscimo significativo do primeiro para o segundo período de avaliação, devido a um excesso de umidade e a uma baixa insolação (Tabela 1). LUPATINI et al. (1998) encontraram maiores valores de taxa de acumulação nos meses de setembro e outubro, quando as temperaturas foram mais favoráveis ao desenvolvimento

Tabela 3 - Composição botânica da pastagem de aveia preta mais azevém submetida a diferentes fontes de nitrogênio.

Avaliações

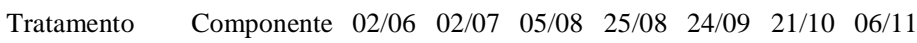

\begin{tabular}{ccccccccc}
\hline \multirow{5}{*}{ Uréia } & AV & 42,9 & 35,6 & 8,5 & 6,1 & - & - & - \\
& AZ & 30,7 & 45,4 & 74,8 & 88,9 & 83,1 & 76,2 & 51,6 \\
& OG & 22,8 & 17,4 & - & - & - & - & - \\
& MM & 3,6 & 1,2 & 16,7 & 5,0 & 16,9 & 23,8 & 48,4 \\
\multirow{5}{*}{ Sulfato de amônio } & & & & & & & & \\
& AV & 61,1 & 31,0 & 13,4 & 10,2 & - & - & - \\
& OG & 18,8 & 30,7 & 72,3 & 82,7 & 81,7 & 72,9 & 53,2 \\
& MM & - & 11,1 & 14,3 & 7,1 & 18,3 & 27,1 & 46,8 \\
\hline
\end{tabular}

AV - Aveia preta; AZ - Azevém; OG - Outras gramíneas; MM - Material morto. do azevém; deve-se ressaltar que, naquele trabalho, o pastejo foi iniciado em agosto. Com a antecipação da utilização da pastagem, parece não haver picos de produção tão pronunciados nos meses de setembro e outubro, pois ocorre uma boa produção no mês de junho quando o fotoperíodo ainda permite um bom crescimento das plantas.

A produção total de MS (Tabela 2), da semeadura (21/04) até o final da utilização $(08 / 11)$, foi semelhante $(\mathrm{P}>0,05)$ entre as fontes de $\mathrm{N}$ usadas. $\mathrm{Ob}-$ tiveram-se produções de 7410 $\mathrm{kg} / \mathrm{ha}$ de MS usando-se uréia, e $6618 \mathrm{~kg} / \mathrm{ha}$ de MS usando-se sulfato de amônio, o que não confirma a observação empírica do produtor de que o sulfato de amônio é mais eficiente que a uréia, como fonte de nitrogênio em cobertura para gramíneas anuais de inverno.

As diferentes fontes de $\mathrm{N}$ usadas podem influenciar nas quantidades de $\mathrm{N}$ propensas a perdas, como demonstram ANJOS e TEDESCO (1976), em condições tropicais, utilizando $200 \mathrm{~kg} / \mathrm{ha}$ de $\mathrm{N}$, determinaram perdas de $\mathrm{NH}_{3}$ por volatilização de 17,3 e $0,7 \%$ do $\mathrm{N}$ aplicado, e recuperação de 73,3 e 93,7\% do $\mathrm{N}$ aplicado, respectivamente, para uréia e sulfato de amônio. No presente experimento, a produção total de MS por hectare foi semelhante para as duas fontes. Esses resultados indicam que não ocorreram diferenças nas perdas de $\mathrm{N}$, provavelmente porque a fertilização foi conduzida com o solo em boas condições de umidade e sua aplicação realizada nas horas menos quentes do dia, em plantas em pleno estágio de crescimento e com bom resíduo foliar na pastagem.

O percentual dos componentes botânicos dos resíduos são apresentados na tabela 3. Observa-se maior contribuição inicial da aveia preta, representando 42,9 e $61,1 \%$; por outro lado, no final de setembro, representou apenas 6,1 e 10,2\% do resíduo, para uréia e sulfato de amônio, respectivamente. Isso evidencia a precocidade de produção da aveia preta como opção para amenizar a falta de alimento durante o final do outono e início do inverno, período em que o azevém apresenta baixa produção. A 
partir de agosto, o azevém apresentou maior contribuição no resíduo total, atingindo valores de 74,8 e $72,3 \%$ para uréia e sulfato de amônio, respectivamente. Essas observações encontram respaldo na afirmação de FLOSS (1989), de que a aveia preta apresenta um rápido crescimento inicial, com a diminuição da produção nos períodos posteriores, e de que o azevém apresenta desenvolvimento lento em temperaturas baixas e aumenta a produção de MS quando as temperaturas são mais elevadas.

A fonte de nitrogênio não afetou de forma significativa os teores de MS, PB e DIVMO (Tabela 4). O teor de MS foi de 18,26 e 18,47\% para uréia e sulfato de amônio, respectivamente. A diferença encontrada foi entre períodos de avaliação, ou seja, a partir do terceiro período, o teor de matéria seca aumentou linearmente, acompanhando o avanço no ciclo vegetativo das espécies. Do primeiro até o terceiro período, não ocorreu diferença significativa porque o aparecimento do azevém (Tabela 3) fez com que o teor de MS do resíduo não aumentasse, devido ao elevado conteúdo de água que essa espécie possui no início do ciclo vegetativo.

A DIVMO do resíduo foi de 57,85 e $57,04 \%$ para uréia e sulfato de amônio respectiva-

Tabela 4 - Percentagem de Matéria seca, teores de proteína bruta (PB) e digestibilidade in vitro da matéria orgânica (DIVMO) da pastagem de aveia preta + azevém submetida a duas fontes de nitrogênio.

\begin{tabular}{|c|c|c|c|c|c|c|c|}
\hline \multirow[b]{2}{*}{ Tratamentos } & \multicolumn{6}{|c|}{ Períodos } & \multirow[b]{2}{*}{ Médic } \\
\hline & $\begin{array}{c}02 / 06 \\
a \\
02 / 07\end{array}$ & $\begin{array}{c}02 / 07 \\
\mathrm{a} \\
05 / 08\end{array}$ & $\begin{array}{c}05 / 08 \\
a \\
25 / 08\end{array}$ & $\begin{array}{c}25 / 08 \\
a \\
24 / 09\end{array}$ & $\begin{array}{l}24 / 09 \\
a \\
21 / 10\end{array}$ & $\begin{array}{c}21 / 10 \\
a \\
06 / 11\end{array}$ & \\
\hline & \multicolumn{7}{|c|}{ MS (\%) } \\
\hline $\begin{array}{c}\text { Uréia } \\
\text { Sulfato de amônio } \\
\text { Média }\end{array}$ & $\begin{array}{c}14,76 \\
14,75 \\
14,75 \mathrm{~d} *\end{array}$ & $\begin{array}{c}15,52 \\
15,58 \\
15,55 \mathrm{~d}\end{array}$ & $\begin{array}{c}13,82 \\
14,65 \\
14,23 \mathrm{~d}\end{array}$ & $\begin{array}{c}17,93 \\
18,79 \\
18,36 \mathrm{c}\end{array}$ & $\begin{array}{c}21,14 \\
21,58 \\
21,36 b\end{array}$ & $\begin{array}{c}33,21 \\
31,24 \\
32,23 \mathrm{a}\end{array}$ & $\begin{array}{l}18,26 \\
18,47\end{array}$ \\
\hline & \multicolumn{7}{|c|}{ DIVMO (\%) } \\
\hline $\begin{array}{c}\text { Uréia } \\
\text { Sulfato de amônio } \\
\text { Média }\end{array}$ & $\begin{array}{c}65,19 \\
65,18 \\
65,19 a^{*}\end{array}$ & $\begin{array}{c}61,01 \\
59,58 \\
60,30 b\end{array}$ & $\begin{array}{r}58,20 \\
57,06 \\
57,63 \mathrm{c}\end{array}$ & $\begin{array}{c}55,79 \\
55,28 \\
55,53 \mathrm{c} \\
\text { PB (\%) }\end{array}$ & $\begin{array}{c}52,49 \\
51,69 \\
52,09 d\end{array}$ & $\begin{array}{c}51,45 \\
50,30 \\
50,87 \mathrm{~d}\end{array}$ & $\begin{array}{l}57,85 \\
57,04\end{array}$ \\
\hline $\begin{array}{c}\text { Uréia } \\
\text { Sulfato de amônio } \\
\text { Média }\end{array}$ & $\begin{array}{c}22,78 \\
23,34 \\
23,06 \mathrm{~b} *\end{array}$ & $\begin{array}{r}22,36 \\
23,60 \\
22,98 b\end{array}$ & $\begin{array}{c}25,44 \\
26,19 \\
25,82 \mathrm{a}\end{array}$ & $\begin{array}{c}23,58 \\
23,97 \\
23,78 \mathrm{ab}\end{array}$ & $\begin{array}{c}20,30 \\
20,17 \\
20,29 \mathrm{c}\end{array}$ & $\begin{array}{c}15,36 \\
15,62 \\
15,49 \mathrm{~d}\end{array}$ & $\begin{array}{l}22,14 \\
22,69\end{array}$ \\
\hline
\end{tabular}

*Médias na linha com letras diferentes diferem $(\mathrm{P}<0,05)$ pelo teste $\mathrm{t}$. mente. A diferença significativa encontrada foi entre períodos de avaliação, em que houve um decréscimo do primeiro para o terceiro período e do quarto para o quinto período de avaliação. A queda nos teores de DIVMO com o avanço dos períodos é corroborada por BLASER (1990) que com o avanço dos estágios de desenvolvimento das plantas ocorre um aumento dos tecidos de sustentação constituídos por carboidratos estruturais.

Em relação ao teor de $\mathrm{PB}$, os valores encontrados foram de 22,14 e $22,69 \%$ para uréia e sulfato de amônio, respectivamente. Esses resultados são superiores aos reportados por LESAMA (1997), que encontrou $10,4 \%$ de PB para a mesma mistura forrageira. Já ROSO (1998) encontrou valores semelhantes (20,31\%). Esses valores de PB evidenciam o grande potencial das pastagens de inverno, quando fertilizadas com níveis adequados de nitrogênio, como fonte de PB para o animal, possibilitando ganhos de peso elevados. No que se refere aos períodos de avaliação, houve diferença significativa, sendo que o maior teor de PB foi no terceiro período $(25,82 \%)$ devido a uma grande porcentagem de azevém em intenso afilhamento. $\mathrm{O}$ valor mais baixo de PB foi obtido no último período $(15,49 \%)$, pois as plantas de azevém já se encontravam em final de ciclo.

A queda no teor de $\mathrm{PB}$ com o avanço nos estágios de desenvolvimento ocorreu devido à perda de folhas, ocasionadas, pelo pastejo seletivo, e ao decréscimo natural na relação folha/caule $(\mathrm{F} / \mathrm{C})$ pela elongação dos primórdios florais, bem como a uma acelerada taxa de acumulação de materiais estruturais. Isso também foi observado por LESAMA (1997) sendo que a aveia preta partiu de uma relação $\mathrm{F} / \mathrm{C}$ de 0,85 no mês de agosto e chegou a uma relação de apenas 0,43 no mês de setembro. O mesmo comportamento foi verificado para o azevém, que apresentava uma relação $\mathrm{F} / \mathrm{C}$ de 1,19 no mês de agosto, caindo para 0,53 no mês de outubro. Segundo CORSI (1984), a porção de melhor qualidade é aquela formada por folhas em expansão ou recém expandidas. Desta forma, com o decréscimo na relação $\mathrm{F} / \mathrm{C}$, ocorre uma diminuição da qualidade da pastagem.

O custo total da pastagem/ha, incluindo arrendamento 
( $\mathrm{R} \$ 30,00)$, mecanização ( $\mathrm{R} \$ 34,00)$, adubação de base $(\mathrm{R} \$ 56,00)$ e sementes $(\mathrm{R} \$ 69,00)$, uréia ( $R \$ 106,70)$ ou sulfato de amônio $(\mathrm{R} \$ 190,48)$, foi de $\mathrm{R} \$ 295,70$ e $\mathrm{R} \$ 379,40$, respectivamente, para uréia e sulfato de amônio. A adubação nitrogenada representou $36,08 \%$ e $50,20 \%$ do custo total, e custo $/ \mathrm{kg}$ de matéria seca produzida foi de $\mathrm{R} \$ 0,039$ e $\mathrm{R} \$ 0,057$, respectivamente para uréia e sulfato de amônio. Esses resultados mostram que, embora não havendo diferença significativa na produção de matéria seca, o custo/kg MS produzida foi 31,57\% inferior quando a uréia foi usada como fonte de nitrogênio. Como num dado momento essas fontes nitrogenadas podem apresentar variações nos preços e na disponibilidade, deve ser levado em consideração na escolha da fonte de $\mathrm{N}$ a ser utilizada, o preço por quilograma de nitrogênio aplicado, uma vez que não houve diferença na produção de forragem entre elas.

\section{CONCLUSÕES}

A produção e a qualidade da forragem da mistura aveia preta e azevém não foram influenciadas pelas fontes de $\mathrm{N}$ (uréia e sulfato de amônio) aplicadas em cobertura.

$\mathrm{O}$ preço por $\mathrm{kg}$ de $\mathrm{N}$ aplicado deve ser considerado no momento da escolha da fonte nitrogenada a ser utilizada na pastagem.

\section{AGRADECIMENTO}

Agradecemos ao Professor José Henrique Souza da Silva pela contribuição valiosa na análise estatística deste trabalho.

\section{REFERÊNCIAS BIBLIOGRÁFICAS}

ANJOS, J.T., TEDESCO, M. J. Volatilização de amônia proveniente de dois fertilizantes nitrogenados aplicados em solos cultivados. Científica, Jaboticabal, v.4, n.1, p.49-55, 1976

AOAC - ASSOCIATION OF OFFICIAL ANALYTICAL CHEMISTS. Official methods of analysis. 14 ed. Washington : AOAC, 1984. 1141p.

BLASER, R.E. Manejo do complexo pastagem-animal para avaliação de plantas e desenvolvimento de sistemas de produção de forragens. In: PASTAGENS, 1990, Piracicaba - SP. Anais... Piracicaba : FEALQ, 1990. 205p. p.157-205.
CORSI, M. Uréia como fertilizante na produção de forragem. In.: SIMPÓSIO SOBRE NUTRIÇÃO DE BOVINOS, 2, 1984, Piracicaba - SP. Anais... Piracicaba : FEALQ, 1984. p.275-308.

FLOSS, E.L. Aveia. In: BAIER, A.C., AUDE, M.I.S., FLOSS, E.L. As lavouras de inverno-1. 2 ed. São Paulo : Globo, 1989. p.76-106.

LESAMA, M.F. Produção animal em gramíneas de estação fria com fertilização nitrogenada ou associadas com leguminosa, com ou sem fertilização nitrogenada. Santa Maria - RS, 1997. 129p. Dissertação (Mestrado em Zootecnia) - Curso de Pós-graduação em Zootecnia, Universidade Federal de Santa Maria, 1997

LUPATINI, G. C., RESLTE, J, CERETA, M. et al. Avaliação da mistura de aveia preta (Avena strigosa) e azevém (Lolium multiflorum) sob pastejo, submetida a níveis de nitrogênio. Revista Pesquisa Agropecuária Brasileira, Brasília, v.33, n.11, p.1939-1943, 1998.

MALAVOLTA, E. Os elementos minerais. Elementos de nutrição mineral de plantas. São Paulo : Agronômica Ceres. 1980. p.104-216.

MORENO, J.A. Clima do Rio Grande do Sul. Porto Alegre : Secretaria da Agricultura, 1961. 41p.

RECOMENDAÇÕES de adubação e calagem para os estados do Rio Grande do Sul e Santa Catarina. 3 ed. Passo Fundo : SBCS, Núcleo Regional Sul - EMBRAPA - CNPT, 1995. 223p.

RESTLE, J.; LUPATINI, G. C.; VALENTE, A. V., et al. Avaliação da mistura de aveia preta (Avena strigosa) e azevém (Lolium multiflorum) sob pastejo submetida a níveis de nitrogênio. In.: REUNIÃO ANUAL DA SOCIEDADE BRASILEIRA DE ZOOTECNIA, 30, 1993, Rio de Janeiro RJ. Anais... Niterói - RJ : Soc Bras Zootecnia, 1993. p.71.

RESTle, J., LUPATINI, G.C., ROSO, C., et $\boldsymbol{a l}$. Eficiência e desempenho de diferentes categorias de bovinos de corte em pastagem cultivada. Revista Brasileira de Zootecnia., Viçosa, v.27, n.2, p.397-404, 1998.

ROSO, C. Produção animal em misturas de gramíneas anuais de estação fria. Santa Maria - RS, 1998. 104p. Dissertação (Mestrado em Zootecnia) - Curso de Pós-graduação em Zootecnia, Universidade Federal de Santa Maria, 1998.

SAS, Institute Inc. SAS Language reference. Version 6. Cary, NC : SAS, 1990. 1042p.

TILLEY, J.M.A., TERRY, R.A. A two- stage technique for the in vitro digestion of forage crop. Journal British Grassland Society, Hurlev, v.18, n.2, p.104-111, 1963. 